\title{
Bannock as medicine
}

Cite as: CMAJ 2018 March 19;190:E335-6. doi: 10.1503/cmaj.170875

CMAJ Podcasts: article reading at https://soundcloud.com/cmajpodcasts/170875-enc

\author{
t's been difficult to figure out who I \\ am. \\ Doctor? In training. \\ Métis? Yes.
}

Knowing what it means to be Métis? Not fully yet.

Knowing how it really feels to be Indigenous and marginalized in Canada? Not a clue.

The history of Métis people stems from rejection: first, rejection by the First Nations (because we're half-white), then rejection by the early European culture (because we're half-Indigenous). From this came a need for inclusion and the creation of our own nation with a distinct culture, language and homeland: "half-breeds" became Métis. But that was only the beginning of our common struggle, our crisis of identity. How Indigenous are we? How much do we share in the same inequalities and racism as our First Nations or Inuit brothers and sisters?

Personal circumstance complicates my own crisis of identity. My parents separated when I was young, and I was raised solely by my nonMétis mother. I grew up learning respect toward Métis and Indigenous peoples, but without learning their history, culture and teachings. My well-meaning classmates would see my pale skin and ask: "How Indigenous are you?" It was the same question that I was always asking myself.

In the infancy of my clinical training, I was determined to connect with Indigenous patients and stop seeing their identity as a pathology or risk factor as I'd often been taught. During a social pediatrics elective in medical school, I connected with one family when I spent four days at an organization dedicated to outreach and comprehensive care for mothers who used drugs during pregnancy or who were at risk for relapse. I met a woman and her four-month-old baby girl, both of whom were First Nations, on two occasions.
On the second occasion, we made bannock, also called fry bread. One cup of flour. Three-quarter cup of water. Baking powder. Salt.

I was nervous. It's a staple and simple food for many Indigenous people, and I didn't want my lack of common knowledge to show.

This woman showed me how she makes it, preferring to have her dough a bit runnier than mine, which led to explosion-shaped pieces when dropped in hot vegetable oil to cook. I wondered who taught her the recipe. Was it her kokum (grandmother)? Was it the Internet (like me)?

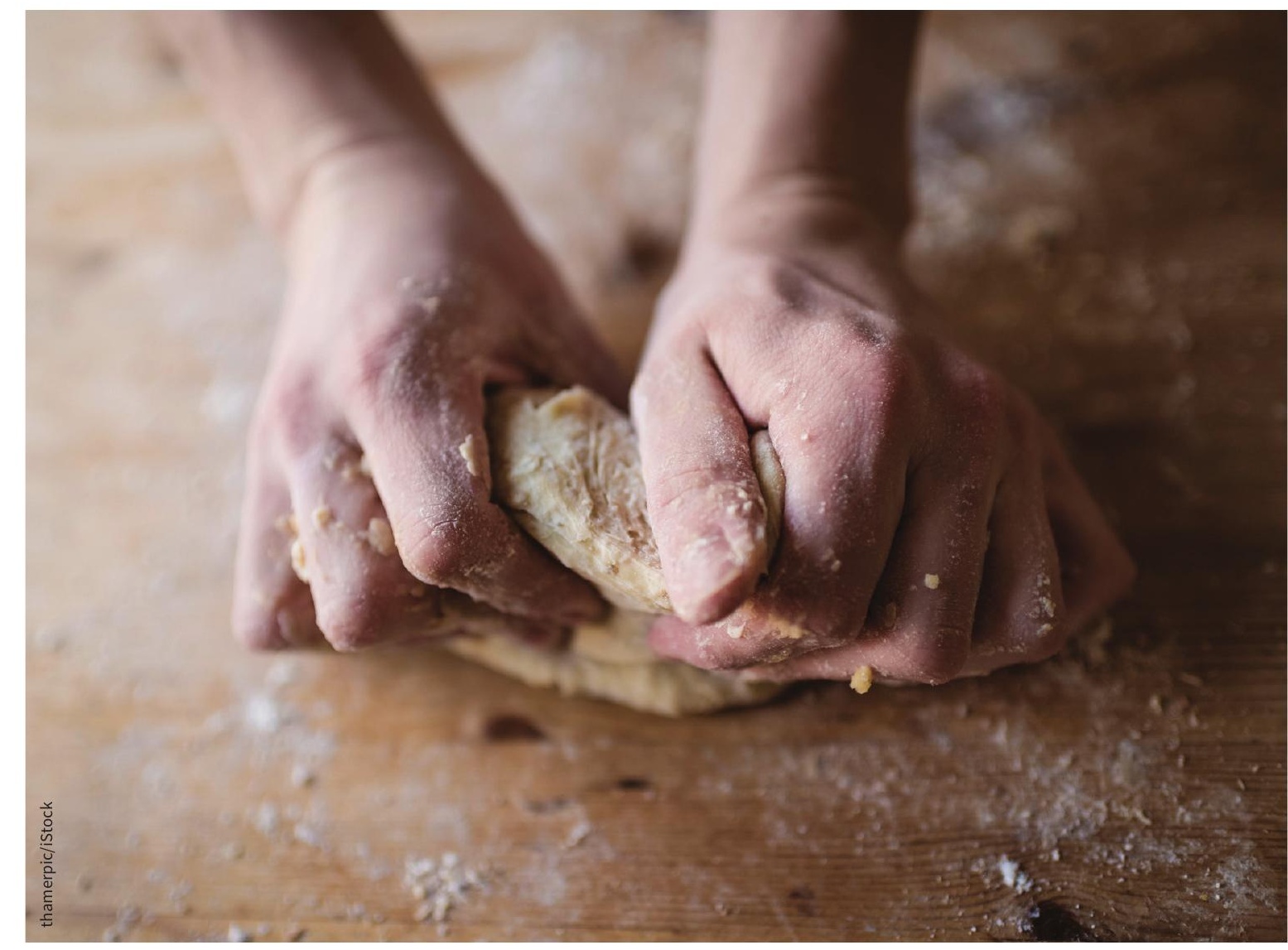


We made our bannock, watching her daughter play with the early childhood educator on the couch not far away. She smiled at me and her daughter, but didn't have much to say. She looked away when I asked her about where she learned how to make bannock. I saw a bannock recipe open on her phone.

I knew that she was First Nations, but I also knew that she was adopted into a non-First Nations family as a child. She grew up absent of her culture and teachings, as I had. Was she having a crisis of identity as I was?

Yet here we were, armed with our Internet recipes, making bannock and sharing it with the staff and other mothers in the centre, learning from each other.

Before she left for the day, she asked me to hold her daughter for a few min- utes. Her daughter was inquisitive (what were those wire circles on my face?), playful (another toy goes into her mouth) and developing (she can roll!). I wondered what she would grow up to understand about her heritage and herself. Giving her back into her mother's arms, I wished them well, because I wouldn't be seeing them again.

I cannot say how this woman felt. I would like to imagine that she felt comforted knowing that there were Métis doctors in training who cared for her and her daughter's health. I would like to hope that she realized that each step in her journey to understand herself, even as small as making bannock from an Internet recipe, was a step toward reconciliation and to bettering her health.
For me, I felt content because I had connected through my identity. In doing so, I had shared in self-discovery and felt better for it.

I felt comforted in the fact that I, too, needed bannock as medicine.

\section{Ryan Giroux MD}

Department of Paediatrics, University of Toronto, Toronto, Ont.

This article has been peer reviewed.

This is a true story. The patient has given her consent for this story to be told.

"Wherever the art of medicine is loved, there is also a love of Humanities." - Hippocrates 